\title{
ESTIMATIVA DA HERDABILIDADE* DO DIABETES JUVENIL EM UMA POPULAÇÃO BRASILEIRA
}

Calógeras A. de A. Barbosa**

BARBOSA, C. A. de A. Estimativa da herdabilidade do diabetes juvenil em uma população brasileira. Rev. Saúde públ., S. Paulo, 18:382-5, 1984.

RESUMO: A herdabilidade da suscetibilidade do diabetes juvenil em uma população brasileira é estimada baseando-se em informaçôes da prevalência da doença na população em geral e entre os pais de afetados. A estimativa de $90 \%$, então obtida, sugere uma alta participação de fatores genéticos na determinação da moléstia. Exemplifica-se a aplicação desse resultado no cálculo de risco de recorrência do diabetes em familiares de indivíduos afetados.

UNITERMOS: Diabetes mellitus juvenil, prevalência.

\section{INTRODUÇÃO}

A simples observação de que a prevalência de uma doença é mais alta entre os familia. res de indivíduos afetados do que na popula. ção geral, sugere que fatores genéticos são importantes na sua determinação. No entanto, é preciso reconhecer que a agregação fa. miliar não se fundamenta apenas em causas genéticas, e que o ambiente comum também contribui para a semelhança entre indivíduos aparentados. A avaliação da importância relativa que essas duas classes de fatores (genética e ambiental) desempenham na determinação de um estado mórbido é um dos objetivos centrais da epidemiologia genética. Para tanto, reconhece-se que na população geral existe uma variabilidade tal que faz com que algumas pessoas sejam afetadas e outras não, e se deseja saber que fração dessa variabilidade é atribuível a diferenças genéticas entre os indivíduos.

Uma das medidas do componente genético de uma característica (ou doença) é a herdabilidade $\left(\mathrm{h}^{2}\right)$, conceituada como a proporção da variância fenotípica devida a ação de genes aditivos ${ }^{4}$.

$\mathrm{Na}$ literatura existem vários métodos que objetivam estimar a herdabilidade e todos eles se baseiam na correlação fenotípica en- tre os individuos de uma mesma genealogia. Neste trabalho procuramos estimar a importância relativa de fatores genéticos na deter. minação do diabetes juvenil, aplicando um dos métodos tradicionais da genética huma$\mathrm{na}^{2}$ aos dados de prevalência da moléstia em uma população brasileira ${ }^{1,8}$.

\section{O MÉTODO}

Apenas um breve resumo do método de Falconer ${ }^{2}$ é apresentado a seguir: considerando-se uma doença qualquer, os indivíduos de uma população podem ser fenotipicamente classificados como normais e afetados. Admite-se que relacionada às causas dessa dicotomia fenotípica existe uma distribuição hipotética contínua de um atributo gradual, chamado suscetibilidade, que se pudesse ser medido nos mostraria que acima de um determinado ponto limiar da escala os indivíduos seriam afetados e abaixo dele seriam normais ${ }^{9}$. A palavra suscetibilidade aqui se refere não apenas às tendências inatas do indivíduo mas engloba um conjunto de condiçoes externas ambientais que atuando como um todo torna o indivíduo mais ou menos provável de manifestar a doença. Por-

\footnotetext{
* Embora o termo herdabilidade não esteja incorporado à língua portuguesa, é largamente empregado em epidemiologia genética, significando índice de medida de herança biológica.

* Do Departamento de Ciências da Saúde da Universidade Federal de São Carlos. Via Washington Luiz, km 235 - Caixa Postal 676 - 13560 - São Carlos, SP - Brasil.
} 
BARBOSA, C. A. de A. Estimativa da herdabilidade do diabetes juvenil em uma população brasileira. Rev. Saúde públ., S. Paulo, 18:382-5, 1984.

tanto, podemos dizer que a distribuição da suscetibilidade $S$ tem um componente $g$ que resume as causas genéticas da variabilidade de $S$, e um componente $a$ que se refere às causas ambientais, permitindo escrever:

$$
\mathrm{S}=\mathrm{g}+\mathrm{a} \text {. }
$$

O componente genético $g$, por sua vez, pode ser subdividido em uma fração devida a genes aditivos, isto é, que somam seus efeitos, e uma fração devida aos efeitos de dominância. Aqui consideramos apenas as doenças em que o componente genético é determinado por um conjunto de genes com efeitos individuais aditivos, pequenos em rela. ção à variabilidade geral.

A herdabilidade $\left(h^{2}\right)$ pode ser estimada através do coeficiente de regressão (b) da suscetibilidade dos parentes na suscetibilidade dos afetados, pela seguinte fórmula:

(1) $\quad \mathrm{b}=\mathrm{r} \cdot \mathrm{h}^{2}$

onde $r$ é o coeficiente de correlação entre pa. rentes.

As prevalências da doença na população geral $\left(q_{p}\right)$ e nos familiares dos afetados $\left(q_{f}\right)$ são as únicas informaçðes disponíveis para se estimar o componente genético. Portanto, o coeficiente de regressão $b$ deve ser expresso em termos das prevalências $q_{p}$ e $q f$.

Falconer ${ }^{2}$ mostra que, transformadas as prevalências $\mathrm{q}_{\mathrm{p}}$ e $\mathrm{q}_{\mathrm{f}}$ em desvios ( $\mathrm{x}_{\mathrm{p}}$ e $\mathrm{x}_{\mathrm{f}}$, respectivamente) da distribuição normal reduzida, podemos escrever:

$$
\mathrm{b}=\left(\mathrm{x}_{\mathrm{p}}-\mathrm{x}_{\mathrm{f}}\right) / \mathrm{a}
$$

onde $a$ é a razão $z / q_{p}$, isto é, entre a altura $z$ da ordenada da distribuição normal no ponto limiar e $q_{p}$, a prevalência da doença na população geral, como fora anteriormente definido. Os parâmetros $x_{\mathrm{p}}, x_{\mathrm{f}}$ e $a$ podem ser lidos diretamente em tabelas convencionais (Fisher e Yates ${ }^{5}$, 1971).

Substituindo-se (2) em (1), tem-se: (3)

$$
\mathrm{h}^{2}=\left(\mathrm{x}_{\mathrm{p}}-\mathrm{x}_{\mathrm{f}}\right) /(\mathrm{r} \cdot \mathrm{a})
$$

Portanto, conhecendo-se as prevalências de uma doença na população geral e entre os parentes de indivíduos afetados, torna-se possível estimar a importância relativa do genes aditivos na determinação da variabilidade da suscetibilidade à moléstia nessa população.

\section{OS DADOS}

As informações sobre a prevalência do diabetes mellitus em populações brasileiras são bastante escassas. Esse fato se deve às di. ficuldades de deteç̧ão dos casos, uma vez que provas laboratoriais sensiveis, tais como o teste de tolerância à glicose são de aplicação pouco viável em um trabalho de campo. Exames mais simples como a dosagem única da glicemia não oferecem, às vezes, subsídios para o estabelecimento do diagnóstico.

Para este trabalho valemos-nos das informações extraídas do estudo de Wilson ${ }^{8}$ que, para uma população paulista, estimou a pre. valência do diabetes mellitus em cerca de $2,9 \%$.

Por outro lado, em um levantamento de 14.340 casos de diabetes mellitus no Rio de Janeiro, Arduino ${ }^{1}$ registrou 750 pacientes com diabetes juvenil, perfazendo cerca de $5,2 \%$ do total examinado. Considerando que a estimativa de Wilson ${ }^{8}$ possa ser estendida também para o Rio de Janeiro, finalmente podemos dizer que a prevalência do diabetes juvenil nessa população $\left(q_{p}\right)$ é de cerca de 1,5 pacientes por 1.000 habitantes $\left(\mathrm{q}_{\mathrm{p}}=\right.$ $0,052 \times 0,029=0,001508$ ).

Para a estimativa da prevalência da mo. léstia entre os familiares dos afetados baseamo-nos também no trabalho de Arduino ${ }^{1}$. onde foi observado o diagnóstico de diabetes em 19 mães e 23 pais de um total de 317 pacientes portadores de diabetes juvenil. A prevalência da doença entre as mães foi próxima de $6 \%\left(q_{\mathrm{fm}}=19 / 317=0,05994\right)$ e entre os pais foi de cerca de $7 \%\left(q_{\mathrm{fp}}=23 / 317=\right.$ $0,07256)$.

\section{ESTIMATIVA DA HERDABILIDADE}

Sabendo-se que o coeficiente de correlação genética, $r$, entre pais e filhos, é 0,5 , temos então todas as informações necessárias para a estimativa da herdabilidade do diabetes juvenil, que podem ser assim resumidas: $q_{p}=$ prevalência da doença na população $=0,00151$.

$q_{f m}=$ prevalência entre as mães de afetados $=0,05994$. 
BARBOSA, C. A. de A. Estimativa da herdabilidade do diabetes juvenil em uma população brasileira. Rev. Saúde públ., S. Paulo, 18:382-5, 1984.

$\mathrm{q}_{\mathrm{fp}}=$ prevalência entre os pais de afetados $=0,07256$.

$x_{p}=$ distância entre a média da suscetibili. dade da população e o ponto limiar entre normais e afetados (medida em desvio padrão da normal reduzida e obtida em tabelas convencionais) = 2,968 .

$\mathrm{x}_{\mathrm{fm}}=$ distância entre a média da suscetibilidade das mães dos afetados e o ponto limiar $=1,555$.

$\mathrm{x}_{\mathrm{fp}}=$ distância entre a média da suscetibili. dade dos pais dos afetados e o ponto limiar $=1,461$.

a = distância entre a média da suscetibili. dade dos afetados e da população ge$\mathrm{ral}=3,253$.

Substituindo-se esses valores na fórmula (3), podemos estimar a herdabilidade, como está resumido no quadro abaixo:

\begin{tabular}{llll}
\hline $\begin{array}{l}\text { tipo de } \quad b=\left(\mathrm{x}_{\mathrm{g}}-\mathrm{x}_{\mathrm{f}}\right) / \mathrm{a} \\
\text { parentesco }\end{array}$ & $\mathrm{V}_{\mathrm{b} \cdot 10^{-3}}$ & $\begin{array}{c}\mathrm{h}^{2} \pm \text { e.p } \\
(\%)\end{array}$ \\
\hline $\begin{array}{c}\text { mãe } \\
\text { pai }\end{array}$ & 0,434 & 1,187 & $87 \pm 7$ \\
\hline $\begin{array}{l}\text { Média } \\
\text { Ponderada }\end{array}$ & 0,450 & 0,557 & $90 \pm 5$
\end{tabular}

No quadro, $\mathrm{V}_{\mathrm{b}}$ é a variância do coeficiente de regressão $b$ e no presente estudo foi estimada a partir da fórmula:

$$
\mathrm{V}_{\mathrm{b}}=(1 / \mathrm{a})^{2} \cdot\left(1-\mathrm{q}_{\mathrm{f}}\right) /\left(\mathrm{a}^{2} \cdot \mathrm{A}\right) \text {, }
$$

onde $A$ é o número de parantes afetados. O erro padrão da herdabilidade (e.p) é $2 \sqrt{ } V_{b}$.

Os dois coeficientes de regressão do quadro acima, estimados através das informações maternas e paternas, foram combinados ponderando-se cada um deles pelo inverso da sua variância, isto é

$$
\mathrm{b}_{\text {combinado }}=\Sigma \mathrm{W}_{\mathrm{j}}, \mathrm{b}_{\mathrm{j}} / \Sigma \mathrm{W}_{\mathrm{i}}
$$

onde $W_{\mathrm{i}}$ é o inverso da variância de cada coeficiente de regressão $b_{\mathrm{i}}$.

Finalmente, a variância do coeficiente $b$ combinado é aproximadamente igual ao inverso da soma dos pesos $W_{\mathrm{i}}$.

\section{VALOR PREDITIVO}

Na prática do Aconselhamento Genético é de fundamental importância o conhecimento da herdabilidade do diabetes juvenil em nossa população.

Vejamos alguns exemplos simples onde nossas estimativas podem ser empregadas: Suponha que um paciente diabético deseja saber qual a probabilidade de que seu filho seja também diabético. Nesse caso a própria prevalência $\left(\mathrm{q}_{\mathrm{f}}\right)$ entre parentes de primeiro grau responde a questão, isto é, cerca de $6 \%$.

Suponha agora que uma pessoa tendo um sobrinho diabético deseja saber a probabilidade de que seu filho seja afetado. Nesse caso temos que observar que o coeficiente de correlação entre primos é igual a 1/8. Aplicando-se a fórmula (3), obtemos:

$$
0,9=\left(2,968 \cdot \mathrm{x}_{\mathrm{f}}\right) /(0,125 \cdot 3,253)
$$

Daí estimamos $x_{f}=2,602$. Na tabela da distribuição normal pode ser obtida a preva. lência $\left(\mathrm{q}_{\mathrm{f}}\right)$ relativa a esse valor de $\mathrm{x}_{\mathrm{f}}$, isto é, $\mathrm{q}_{\mathrm{f}}=0,46 \%$ ou seja 1 em 217 .

\section{CONSIDERAÇŐES FINAIS}

A estimativa da herdabilidade do diabetes juvenil obtida nesse trabalho é de $0,9 \pm 0,05$. Este valor sugere que o grau de determinação genética da doença em nosso meio é bastante alto, e que os fatores ambientais são de importância secundária no estabelecimento da moléstia. Não podemos daí concluir que as medidas terapêuticas e preventivas, que são componentes do ambiente, venham por isso a ser ineficazes. Os fatores ambientais considerados nas análises excluem os tratamentos especiais que os pacientes requerem.

Valores altos da herdabilidade foram também obtidos em populaçð̃es canadenses e in. glesas $^{3}$. Nesses dois casos a herdabilidade foi calculada para diferentes faixas etárias, e embora se tenha considerado o diagnóstico único de diabetes mellitus, pode ser observado que nas faixas de 0 a 30 anos os valores da herdabilidade estão por volta de $70 \%$. 
BARBOSA, C. A. de A. Estimativa da herdabilidade do diabetes juvenil em uma população brasileira. Rev. Saúde públ., S. Paulo, 18:382-5, 1984.

Alguns autores sugerem ainda que o diabetes juvenil seja uma característica determinada por um gene autossômico recessivo de penetrância incompleta, estimada em $50 \%^{6}$. Pelos métodos estatísticos atuais fica bastante difícil discriminar entre o modelo mendeliano simples com baixa penetrância e a herança multifatorial considerada nesse trabalho. Como acentua Smith ${ }^{7}$, na prática fatores como erros amostrais, distorções na averiguação, mortalidade diferencial, idade variável de início da doença, heterogeneidade etiológica diminuem o poder de discriminação entre os diferentes modos de heran. ça.

Finalmente, é preciso ponderar que as estimativas aqui apresentadas se baseiam em aproximaçōes de dados registrados na lite. ratura e, portanto, sua aplicação deve ser feita com a devida cautela.

BARBOSA, C. A. de A. [An estimate of the inheritability of juvenile diabetes in a Brazilian population]. Rev. Saúde puibl., S. Paulo, 18:382 - 5, 1984.

ABSTRACT: The inheritability of liability to juvenile diabetes in a Brazilian population is estimated from parent-offspring correlation. The high value of the estimate, 0.9 , suggests that genetic factors are the most important causative agents of the disease in this population.

UNITERMS: Diabetes melitus, juvenile, prevalence.

\section{REFERENCIAS BIBLIOGRÅFICAS}

1. ARDUINO, F. Diabetes Mellitus. Rio de Janeiro. Ed. Guanabara Koogan, 1980. p. 140-61 .

2. FALCONER, D. S. The inheritance of liability to certain diseases estimated from the incidence among relatives. Ann. hum. Genet., 29: $51-76,1965$.

3. FALCONER, D. S. The inheritance of liability to disease with reference to diabetes mellitus. Ann. hum. Genet., 31: 1-20, 1967.

4. FALCONER, D. S. Introdução d genética quantitativa. Viçosa, MG, Imprensa Universitária da Universidade Federal de Viçosa, 1981.

5. FISHER, R. A. \& YATES, F. Tabelas estatisticas para pesquisa em biologia, medicina e agricultura. São Paulo, Ed. Universidade de São Paulo/Ed. Polígono, 1971.

6. RUBINSTEIN, P.; SUCIU-FOCA, N. \& NICHOLSON, J. F. Genetics of juvenile dia- betes mellitus: a recessive gene closely linked to HLA and with 50 per cent penetrance. New Engl. J. Med., 297: 1036-40, 1977.

7. SMITH, C. Discriminating between different modes of inheritance in genetic disease. Clin. Genet., 2: 303-14, 1971.

8. WILSON, D. Contribuição para o conhecimento da epidemiologia do Diabetes Melito. Aspectos de sua prevalência na cidade de Jarinu, Estado de São Paulo. Apud LAURENTI, R.; FONSECA, L. A. M. \& COSTA Jr., M. L. Mortalidade por Diabetes Mellitus no município de São Paulo (Brasil). Rev. Saúde públ., S. Paulo, 16:77-91, 1982.

9. WRIGHT, S. The results of crosses between inbred strains of guinea pigs differing in number of digits. Genetics, 19: 534-51, 1934.

Recebido para publicação em 05/06/1984. Aprovado para publicaçāo em 17/08/1984. 